\title{
Authentic ELT Material Adaptation: Drawbacks, Prevalence and Solutions: The case of Wolkite University community school, Wolkite, Ethiopia.
}

\author{
Fikremariam Yirgu Wondimtegegn \\ College of Social Science and Humanities, Department of English Language and Literature, Wolkite \\ University, Ethiopia.
}

\begin{abstract}
This paper examines the contributing issues that enhance students learning through adapting ELT materials and assessing its effectiveness forwarding to take measures. The study used both qualitative and quantitative approaches. The study was conducted a research by developing questionnaire, observation and document analysis. The data were collected from principals, teachers, students and woreda education officers. The data collected were arranged and organized for analysis and interpretation. Based on the analysed data, the study found out that limitations in the implementation of authentic material adaptation and how to use various adaptive techniques. Teachers lack of motive and interest to design and select language materials that fit the curriculum and closely correspond with the aims of the teaching program and the needs of the students. Thus, the study recommended that adapted materials should be carefully evaluated and selected before being used for a language classroom.
\end{abstract}

Key words: Authentic, Material Adaptation, ELT materials

\section{Introduction}

Authentic material adaptation in language learning in line with the students' level of understanding, the relationship among their culture, norms, and values play a significant role in their academic endeavour. Therefore, authentic material adaptations are ways how to improve learner's use of the materials that have great importance especially for ELT classes. Moreover, in language teaching and learning process adapting authentic material is mandatory issue to develop students' command of English.

The research is a study on authentic material adaptation in EFL classes it focuses on the drawbacks, prevalence and way forwarding on the development of language fluency and accuracy. Thus, applying a new curriculum in place does not necessarily mean that a change in classroom behaviour will occur (Harrison, 1996:299). This is because innovation in the language teaching classrooms is often hindered by the lack of explicit illustrations of good practice (Caldin, cited in Pekky 1988:Xi). Besides, authentic materials have a permanent influence on the students' academic performance and in making of their minds, taking responsibilities and comprehending the text.

Many scholars believed that, language learning depends on immersing students not only in 'comprehensible input' but also in adapted authentic tasks that require them to negotiate meaning and to engage in naturalistic and meaningful communication. While students are engaged in such kinds of tasks, which need their cognitive abilities, it is assumed that they will develop both accuracy and fluency of the language (Richards and Rodgers, 2001; Ellis, 2003; Willis, 2004). 
The overall effect is that learners who repeatedly show over confident their performance can motivate for learning due to self-confidence and the authenticity of the material adapted in line with their culture. Similarly, students who use inauthentic materials affect their performance may be at a disadvantage as their motivation to learn English language with regards to adapting new materials for them. Nunan (1989) explains that classroom teaching and learning experiences are more important than statement of intent in determining language learning outcomes. As a result, designing appropriate and authentic teaching materials according to the desire of the students' language experience and background knowledge, culture, norm, customs, etc. to enhance their language learning.

The ability to use the text correctly and appropriately is likely to give teachers' confidence while teaching. It would seem to follow that students too, need to have familiar text if they are to pursue their education confidently. However, if either of the text is unfamiliar it is likely that the teaching and learning will be hampered. In the teaching learning process of language skills familiar culture helps the learner to understand the message of the adapted text. The familiarity of text is very important to enhance the studentslanguage competency. In this regard Dodge and Colker (2000) explain:

Because culture is an integral part of student's lives, it should be an integral part of curriculum as well. One way to do this is to make the environment and curriculum reflect the children's background and experience. Meaningful learning starts with children's first-hand experience - family, language, and neighbourhood - and gradually expands upon what is familiar and what children already know.

Madsen andBowen (1978)makethepointclearly:' thegoodteacheris constantly adapting.Headaptswhenheaddsan examplenotfoundinthebook orheadaptseven whenhe referstoan exercise covered earlier,or when heintroducesasupplementarypicture.Therefore, adaptationisessentiallyaprocessofmatching. Its purpose is to maximize the appropriacy of teaching materials in context, by changing some of the internal characteristics of a course book to better suit our particular circumstances. All wright and Bailey (1991: XV) states that ... no matter how much intellectual energy is put in the intervention of new methods, what really matters is what happens when teachers and learners get together in the classroom. In other words, what teachers actually do in their classes plays a decisive role in the successfulness of a language teaching process. If the teachers do not develop the right material, they may not be able to achieve the required changes in their classrooms.

There are strong sheds of evidence that the choice of authentic materials has great effect on students' achievement. This study, therefore, attempts to investigate the authentic teaching material adaptation drawbacks, prevalence and forwarding solutions.

\subsection{Purpose of the Study}

Thepurposeofthestudywasto investigate the authentic teaching material adaptation drawbacks, prevalence and forwarding solutions in EFL Classes: the case of Wolkite University CommunitySchool in Wolkite, Ethiopia.

\subsection{Objectives of the Study}

Themajor objective ofthestudywasto investigate the authentic teaching material adaptation drawbacks, prevalence and forwarding solutions in EFL Classes: the case of Wolkite University CommunitySchool in Wolkite, Ethiopia.

\section{Objectives of the Study}

Thespecificobjectivesofthestudywereto:

$\checkmark$ identifythe drawbacks in using authentic teaching materials in EFL Classes

$\checkmark$ identify the adaptive techniques used in EFL classes;

$\checkmark$ forward solutions to adapt authentic teaching materials

\subsection{Research Questions}


$\checkmark$ What are the drawbacks in using authentic teaching materials in EFL Classes?

$\checkmark$ What arethe adaptive techniques used in EFL classes?

$\checkmark$ What are the solutions to adapt authentic teaching materials?

\subsection{Significance of the Study}

The study was very important because it intended to benefit all stake holders such as the Ministry of Education, education officers and supervisors, school principals, teachersandstudents. The results would help school principals, teachers and students to work together and produce relevant and authentic teaching materials in EFL classes to thestudents.

\section{Review of related Literature}

\subsection{Definition of material adaptation}

An effective teacher has a wide-ranging repertoire of different teaching and learning models, strategies and techniques and knows how to create the right conditions for learning. The choice is determined by the nature of the learning objective. Today's world requires the way of language teaching that can enable learners develop their communicative competence.

This can be realized if, among other things, teachers teach creatively and appositely by adapting teaching authentic materials, methods or techniques according to the situations they are in and by creating contexts which are meaningful for students. In language teaching/ learning, adaptation refers to the process of making some internal changes so as to make a given textbook suitable for particular type of learners. "Adaptation means making the materials meet one's requirements" (Cunningworth, 1984:65).Scholars seem to agree that adaptation (which includes: adding, omitting, modifying etc) is very important activity among language teachers. According to Misirh (2010), adaptation is a requisite part of language teaching/ learning.

Tomlinson (1998) cited in Shameem (2017) outlines the characteristics of good materials as follows: materials should achieve impact; materials should help learners to feel at ease; materials should help learners to develop confidence; learners should perceive learning materials as relevant and useful; materials should require and facilitate learner self-investment; learners must be ready to acquire; the learners' attention should be drawn to linguistic features of the input; materials should provide learners with opportunitiestousethetargetlanguagetoachievecommunicativepurposes, through meaningful, realistic interaction; materials should consider the

Positive effects of instruction tobedelayed,thusincurringrecycling;materialsshouldbeattentivethat learners differ in learning styles; materials should deliberate that learners differ in affective attitudes; materials should permit a silent period at the begging of instruction; materials should maximize learning potential by encouraging intellectual, aes the tic and emotional involvement which stimulates both right and left brain activities; materials should notrely too much on controlled practice; materials should provide opportunities for outcome feedback.

Students of ten experience difficulty in relating their learning to what they know about the world around them. They may also find it difficult to see there levance of what they are learning. This creates barriers to both learning and teaching. In English the use of real-life materials, such as telephone conversation, can enhance the making of these connection sand the generation off normal language knowledge. These materials can be brought to class by the students themselves, furthering involvement in the lesson (Gravemeijer1997). It is important to take in to account here that using real-life examples is more than just using words from everyday life in problems that are, as a whole, unrealistic. Many problems use a context which only at first sight appears realistic. To be effective, a real-life example needs to connect farm or etopupils' actual experience (Ibid) 


\subsection{The Use and Usefulness of adapting authentic teaching materials}

McGrath (2013) cited in Shameem (2017) contends that the importance of materials as content act as a stimulus for communicative interaction, and materials as language serves the purpose of information about the target language and carefully selected examples of use. According to him, following are the advantages of text books: reduce the time needed for lesson preparation; provide a visible, coherent programme of work; provide support; a convenient resource for learners; make standardized instruction possible; visually appealing, cultural artifacts; and contain a wealth of extra materials.

While supporting the idea that teachers should prepare their own materials, Howard and Major (2004) present as et of guidelines for designing effective materials for teaching and learning English: English language teaching materials should be contextualized, attractive, flexible, and authentic. In addition to these, Materials should stimulate interaction and be generative in terms of language; encourage learners to develop learning skills and strategies; allow for a focus on form as well as function; offer opportunities for integrated language use; link to each other to develop a progression of skills, understandings and language items; have appropriate instructions.

Marland (1977: 3) states that "difficulty with language hamper understanding and growth in most areas of learning, and conversely, those areas of learning could provide real context for language growth." Here a reader should note that, a possible source of the difficulty might be the complexity of the adapted text.

If teachers did not master the profession, the knowledge and experience of teachers' language may have negative impact on the students'language competency. Hence, a teacher must take the initiative to master the language. Strevens (1974: 23) states that "A teacher is the learners' model especially as far as the spoken language concerned, as if the teacher's command of language is inadequate, the learners' achievement will be impaired."

The combination of knowledge, decision sand action should provide an impet us for effective teaching in the classroom. Effective teachers promote effective learning in a culture of high expectations. Students achieve more when lessons are well structured and sequenced, when teachers make objectives clear and where students know what they are supposed to be learning. Effective teachers interact with students through targeted prompting and feedback and review learning and student progress regularly. From learners' side one possible source of inability to comprehend the listening text could be lack of sufficient vocabulary and the complexity of the text. Generally, there are various factors that influence the text fall under linguistic problems resulted from sentence length, word length, and newer word.

Authentic material adaptation is a key component in most language teaching and learning process. In an English as a foreign language context, it may even constitute the main and perhaps only source of language input that learners receive and the basis for language practice that occurs both inside and outside the classroom. However, textbooks are not always professionally designed and do not always fit the curriculum and closely correspond with the aims of the teaching program and the needs of the students. Thus, adapted materials should be carefully evaluated and selected before being used for a language classroom. Authentic materials benefit the language teachers and teaching staff select the most appropriate materials available for a specific grade level. It also helps to identify the strengths and weaknesses of a particular textbook that is already in use. Besides, it aids to inform teachers in the process of textbook adaptation and decision-making for the next course.

\subsection{Adaptive Techniques}

Even if the school they work in is highly ineffective, individual teachers can produce powerful gains in student learning by adapting various authentic teaching materials. To adapt authentic language teaching 
materials, the teacher can use different adaptive techniques: Adding, Omitting or deleting, Modifying, Simplifying, and Re-ordering/ Rearrangement.

Addition is an adaptation procedure which involves supplementation of extra linguistic items and activities to make up for the inadequacy/ insufficiency of materials. Deletion is an adaptation procedure which involves removal of some of the linguistic items and activities which are found to be extra and unnecessary. So, deletion is a process in which materials are taken out rather than added. Modification means changes in different aspects of materials, such as linguistic level, exercises, assessment system and so on. Simplification is employed to make materials less complicated or easier to understand. If the language teaching material is found to be difficult or mechanical for the target learner, it (material) can be made suitable for the learner through the process of simplification.Rearrangement/ Re-ordering is a procedure of materials adaptation through which different parts of a course book are arranged in a different order or sequence. Rearrangement of materials helps to make them comparatively more interesting and appropriate for the learner as well as the teacher. It means, when teachers prepare appropriate language material for their respective students by following the adaptive techniques, students have a chance to boost their language competency.

\subsection{Drawbacksin Adapting Authentic Teaching Materials}

Authentic materials have got its own shortcomings or disadvantages which may include: clearly lack in grammatical accuracy, acquisition order or durability of learning (Mishan,2005); do not fit in to the systematized language syllabus (Mishan,2005, Richards,2001); too culturally biased, unnecessarily difficult to underst and out side the language community; too many structures are mixed so lower levels have a hard time decoding thetexts;listeningistoughwithtoomanydifferentaccents;materialscan become easily obsolete (Martinez,2002);design of the materials is a complex task (Nixon,1996);difficult of interesting and accessible materials for beginners level; copyright issues can be a concern (Polio,2014); carelessly chosen materials can be extremelydemotivatingforlearnerssincetheywillfinditdifficult;deciding the authenticity of materials are not easy(Harmer,2007); texts are usually too high level (Richards,2001,Case,2012); they are probably idiosyncratic(Case,2012).

To over come the in adequacy of authentic materials and make them more effective and conducive for the language class, Cook (1981) suggests measures, such as, texts or the exercises that'should be motivating; materials need not be too ephemeral, ratherasup- to-date as possible and have a time less quality of them; materials have to be organised in some way, noticeably linked through themes; it is also advised that the actual content is acceptable educationally or linguistically. In this connection, Pinner (2015) contends that as authentic materials are more difficult due to the originality of the language, it has to be modified for the learners. Since authentic texts are not originally intended for second/foreign language learners, there is the issue of difficulty and ambiguity of usually too higher level of comprehension. There fore, it is the duty of the language teacher to either adapt them or prepare the learners for them.

A subject already touched on is that of clearly linking different part so the lesson and the curriculum. New knowledge needs to be linked to concepts learned earlier and different part so ftheless on should be linked to each other, to knowledge learned earlier and to the curriculum. Subject ideas should not be taught in isolation; a strong focus should be put on the relationship between ideas. This will enable students to be better able to retrieve knowledge from memory and to understand how the learning in one lesson links to learning in others. These link ages must be explicitly taught. Teachers can also use questions that ask a student to relate a newly taught concept to a previously learned idea(Hiebertand Carpenter 1992;Askewetal.1997).

This means that teachers must themselves be aware of the connections between different aspects of their subject and the use and application of the subject in different areas of the curriculum. This highlights the importance of good teacher subject knowledge-about both the subject it self and its contribution to other aspects of learning across the curriculum. This is linked to higher student achievement (MandevilleandLiu1997). 


\section{Methodology}

\subsection{Subjects of the Study}

Grade 6 students' who attended their education at Wolkite University community school and teachers who were teaching English language during 2018/2019, principals, and woreda education officers were selected as the subject of this study.

\subsection{Research Design}

Qualitative and quantitative descriptive research methodology was used to conduct the study. The methodologies further explain the analyses and discussions based on the raw data. Three types of instruments: questionnaires, document analysis and classroom observation were used. Besides, the research design involved pertinent data collection instruments on target samples subjects selected from the whole population.

\subsection{Data collection instruments}

Wolkite University community school has two classrooms. The school has an average of 45 students for Grade 6 level with 2 English Language Teachers. Among these two classrooms which were educated by two different English language teachers and the classrooms were purposefully selected. Furthermore, each of these classrooms was observed to investigate the actual problems in relation to adapting authentic teaching materials for three consecutive months. In short, the data collection instruments were questionnaires, observation and document analysis.

\subsection{Methods of data analysis}

The students' and the teachers' responses for the questionnaire were collected, tallied, quantified and tabulated for elaboration and discussion on the basis of their responses. The document analysis was also organized, analysed and interpreted according to their response to make the analysis and interpretation reasonable. The information elicited from classroom observations were categorized in to 'Yes' or 'No' categories to summarize the adapted materials that were observed and noticed during the language sessions. In short, after the quantitative and qualitative data were obtained using teachers' and students' questionnaire, document analysis, classroom observations, they were analysed, described and explained qualitatively and quantitatively. Based on the findings of the study conclusions and possible recommendations were drawn.

\section{Data Analysis}

The analysis of the students, teachers, principals, and woreda education officers' response revealed that the designed authentic materials clearly lacking rammatical accuracy, acquisition order or durability of learning and do not fit in to the systematized language syllabus. However, the materials are not too culturally biased, unnecessarily difficult to understand outside the language community and also too many structures are mixed so lower levels have a hard time decoding the texts listening is tough with too many different accents.

The designed materialscannot become easilyobsolete because the materials that are designed for students authentic as well as easy to comprehend and to do the tasks. Similarly, most of the participant of the study reported that it is difficult to find interesting and accessible materials for beginners level since teachers are carelessly chosen materials can be extremely demotivating for learners since they will find it difficult and deciding the authenticity of materials are not easy. In addition to these, texts that are adapted are usually too high level and also they are probably idiosyncratic. In short, students' inability to comprehend the adapted text could be lack of sufficient vocabulary and the complexity of the text. 
The choice of the adapted material is determined by the nature of the learning objective. Besides, teaching authentic materials, methods or techniques are chosen according to the situations the students are in and by creating contexts which are meaningful for students. Teachers can also use authentic materials and adaptive techniques that ask a student to relate a newly taught concept to a previously learned idea. Thus, using various adapting techniques help learners and teachers to create a conducive teaching learning process. Thus, teachers replied that they use adding (86\%), omitting (64\%), modifying (52\%), simplifying (76\%), and re-ordering (68\%). From the above table, the researcher can conclude that most teachers use adding (86\%) adapting technique an authentic texts in addition to the students textbook. In addition to these, the researcher elicited from document analysis and observation, teachers lack of motive and interest to design and select that fit the curriculum and closely correspond with the aims of the teaching program and the needs of the students. Thus, adapted materials should be carefully evaluated and selected before being used for a language classroom. Both teachers and students reported that authentic materials benefit not only the language teachers and teaching staff select the most appropriate materials available for a specific grade level but also the students in their language competence.

The students, teachers, principals, and woreda education officers' agreed that adapted English language teaching materials reduce the time needed for lesson preparation (85\%);provide a visible, coherent programme of work (85\%); provide support and a convenient resource for learners $(85 \%)$; make standardized instruction possible $(85 \%)$;

visually appealing,culturalartifacts(85\%); containawealthofextramaterials(85\%); develop students language competence( $85 \%)$;provide real context for language growth(85\%).Therefore, adapting language teaching materials that can enable learners develop their communicative competence.

Further more, adapted English language teaching materials are contextualized, attractive, flexible, and authentic (85\%);stimulate interaction and be generative in terms of language $(85 \%)$; encourage learners to develop learning skills and strategies(85\%);allow for a focus on form as well as function(85\%);offer opportunities for integrated language use(85\%); link to each other to develop a progression of skills, understandings and language items $(85 \%)$; andhave appropriate in structions $(85 \%)$.

The findings of students, teachers, principals, and woreda education officers' viewof authentic material adaptation from the questionnaires contrast with the evidence from the classroom observation and document analysis. First of all, the difference between the balance of content and form was one of the prominent observations. The result of the use of authentic materials of their own practice of authentic material adaptation in the classroom, the observed frequency scores were greater than the expected frequency score. This showed that most teachers follow authentic material adaptation closely. And on table 3 authentic material adaptation could enhance their fluency in English (Q7: frequency score is 86\%). On the other hand, on table 3 teachers tended not to believe authentic material adaptation could improve learners' accuracy in English (Q10: frequency score is 68\%). But both teachers focused on form the evidence from the classroom observation in contrast with the findings of teachers'views of authentic material adaptation from the questionnaires. Thus, there is the difference between perceptions and ELT authentic material adaptation practice.

\section{Conclusion and Recommendation}

\subsection{Conclusion}

In the light of the analysis and the findings of the study, the following conclusions we redrawn.

$\checkmark$ Teachers seemed not to have a complete perception of the theories, practices and methodologies of authentic material adaptation. 
$\checkmark$ Teachers seemed to observe some of its benefits; it could enhance fluency, interaction between teacher and students, interaction among students and also increase students ${ }^{\text {ce }}$ motivation, learning and teaching effectiveness.

$\checkmark$ The teachers seem to be perceived the relevance of authentic material adaptation, even if they lack the proper dedication to apply it in their classroom practically. It is found out that authentic material adaptation is being practiced to some extent in Wolkite University community service school, though the basic principles of the approach are not followed.

$\checkmark$ Limitations were found in the implementation of authentic material adaptation teachers showed that they favour a mixture of authentic material adaptation approach with other teaching approaches, more than they favoured using a truly authentic material adaptation approach.

$\checkmark$ Challenges and possibilities towards the selection and implementation of authentic material adaptation including; teachers' ability to adjust to the teaching context, the plan of appropriate adaptive techniques for fostering of teamwork among students, the participant of the study reported that it is difficult to find interesting and accessible materials for beginners level since teachers are carelessly chosen materials can be extremely demotivating for learners since they will find it difficult and deciding the authenticity of materials are not easy and the design of an appropriate situation for affecting factors of the implementation of adaptive methods.

\subsection{Recommendation}

On the basis of the above findings of the study, the following recommendations are forwarded:

$\checkmark$ Lack of training hinders the effective implementation of adapting authentic materials. Therefore, it is important to conduct in-service training like refreshment courses, workshops, panel discussions, etc. so that the use of adapting authentic materials will be enhanced. In addition to this, Training among colleagues, experience sharing among schools, seminar, and courses organized by official bodies are needed. Therefore, the training should be focused on helping teachers to perceive theories, methodologies and adapting techniques and criteria.

$\checkmark$ Teachers need to develop the habit of drawing supplementary reading texts or selecting adapting authentic materials based on the students' level and interest. Further, devising a number of tasks and extended activities to enable them tackle different tasks strategically.

$\checkmark$ The challenges of implementing authentic material adaptation should be given too much consideration to overcoming potential obstacles those teachers may come across in a material adaptation.

$\checkmark$ Both ELT specialists and the concerned authority select and design textbooks which are suitable for effective pedagogy and tolerably compatible with students' values and culture.

$\checkmark$ Create, evaluate, and revise policies and practices that encourage teachers to engage in professional learning related to authentic material adaptation: woreda or zone and school administrators and relevant leaders should work to establish dedicated professional development time during summer and weekend for language teachers. They should encourage teachers to participate in authentic material adaptation learning opportunities and structure time to allow for collaboration around language teachers. Similarly, administrators could develop policies that more equitably distribute qualified and experienced language teachers across all students in school, woreda, and school networks, especially Wolkite university community school needs much attention.

$\checkmark$ Develop internal capacity in science while seeking external partners with language expertise: School and district leaders should work to build school- and woreda and zone-level capacity around English language teaching. These efforts should include creating learning opportunities for teachers but might also include exploring different models for incorporating language expertise, such as employing language specialists at the elementary level or providing high school language department 
heads with time to observe and collaborate with their colleagues. When developing a strategy for building capacity, school and woreda or zone leaders should consider the trade-offs inherent in such choices.

$\checkmark$ Design a portfolio of coherent learning experiences for language teachers that attend to teachers' individual and context-specific needs in partnership with professional networks, institutions of higher education, cultural institutions, and the broader scientific community as appropriate: Teachers and school and district administrators should articulate, implement, and support teacher language learning opportunities in adapting authentic materials as coherent, advanced sequences of experiences toward larger goals for improving language teaching and learning. Here, too, attention should be paid to building teachers' knowledge and skill in the adapting and adapting practices, in language pedagogical content knowledge, and in language teaching practices. It is critical to support teachers' opportunities to learn how to connect with students of diverse backgrounds and experiences and how to tap into relevant authenticity of knowledge of students and communities.

\section{References}

[1] (2004).Pedagogy and Practice: Teaching and Learning in Secondary Schools. Leadership guide. Crown

[2] Askew, M., Rhodes,V., Brown,M., Wiliam,D. and Johnson,D. (1997) Effective teachers of numeracy: report of a study carried out for the Teacher Training Agency. King's College, London ,School of Education.

[3] Cunning worth, A. (1984). Evaluating and Selecting EFL Teaching Materials. Oxford: Heinemann

[4] Dodge, D.T. and Colker, L. J. (2000). The Creative Curriculum. Washington DC: Teaching Strategies Inc. ExceptionalEducationalQuarterly2,1-9.

[5] Ellis, R., 2003. Task based language learning and teaching. Oxford: Oxford University Press.

[6] Gravemeijer, K. (1997)‘ Mediating between concrete and abstract'.In T.Nunes and P.Bryant (eds) Learning and teaching mathematics: an international perspective. Psychology Press. ISBN:0863774555.

[7] Hiebert,J. and Carpenter,T.P.(1992)'Learning and teaching with understanding'.In D.A.Grouws(ed) Handbook of research on mathematics teaching and learning. Macmillan.ISBN:0029223814.

[8] Howard,J. \& J.Major. (2004). Guidelines for designing effective English language teaching materials. Retrieved from http://www.paaljapan.org/resources

[9] Madsen, K. S. and J.D.Bowen (1978): Adaptation in Language Teaching. Rowley, MA: Newbury House.

[10] Mandeville, G.K. and Liu,Q. (1997)'The effect of teacher certification and task level on mathematics achievement'. Teaching and Teacher Education13(4), 397-407.

[11] McGrath, I.(2013). Teaching Materials and the Roles of EFL/ESLTeachers: Practice and Theory. London: Bloomsbury.

[12] Mishan, F. (2005) Designing Authenticity in to Language Learning Materials, Bristol: Intellect.

[13] Misirh, S. (2010) Materials in TEFL: A discussion of what lies behind them and implications: humanizing language Teaching retired on August 2010 from http/www.h/tmag.co.uk/aug10/start04.ltm

[14] Richards, J. and J. Rodgers, 2001. Approaches and methods in language teaching. Cambridge: Cambridge University Press.

[15] Rixon, S. (1990). Developing Listening Skills. London: McMillan Publishers Ltd.

[16] Shameem Ahmed (2017). Authentic ELT Materials in the Language Classroom: An Overview. Journal of Applied Linguistics and Language Research. Volume4, Issue2, 2017,pp.181-202

[17] Stevens, R. and Rosenshine,B. (1981)'Advances in research on teaching'. 
[18] Tomlinson, B. (Ed.) (1998). Materials Development in Language Teaching. Cambridge: Cambridge University Press.

[19] Willis, J., 2004. Perspectives on task-based instruction: Understanding our practices, acknowledging different practitioners. In Leaver, B.L and Willis, J.R. (Eds.), Task-based Instruction in Foreign language Education: practices and Programs. Washington, D.C: Georgetown University Press. 